\title{
Inhalt.
}

Kapitel I.

§ 1: Das Wesen der Klage auf Feststellung streitiger Konkursforderungen $\ldots \ldots \ldots \ldots \ldots \ldots \ldots \ldots \ldots \ldots \ldots, \quad 1-10$

Kapitel II.

Die zuständigen Gerichte und die Verfahrensarten.

§ 2: A. Ŏrtliche und sachliche Zuständigkeit der ordent- Seite lichen Gerichte ....................... 10-12

§ 3: B. Urkunden- und Wechselprozeß ........... 12-15

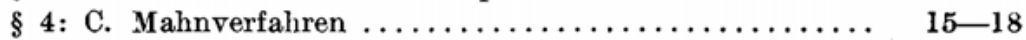

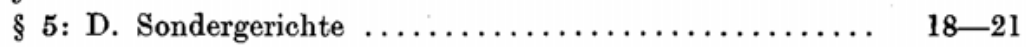

§ 6: E. Strafgerichte $\ldots \ldots \ldots \ldots \ldots \ldots \ldots \ldots \ldots \ldots \ldots \ldots, 21-24$

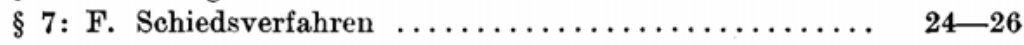

§ 8: G. Ausländische Gerichte $\ldots \ldots \ldots \ldots \ldots \ldots \ldots \ldots \ldots .27$

Kapitel III.

§ 9: Die Parteien und die Konstruktion der Aufnahme eines schwebenden Rechtsstreites insbesondere...........

Kapitel IV.

Das rechtliche Interesse.

§ 10: I. Das Rechtsschutzinteresse im allgemeinen .......

II. Das Interesse an der Feststellung des Konkursgläubigerrechts in subjektiver Hinsicht.

§ 11: Die Betreibung der Feststellung nicht titulierter An-

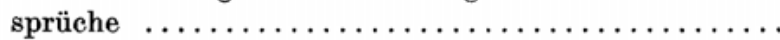

§ 12: Die Aufnahme schwebender Rechtsstreitigkeiten ....

$\S 13$ : III. Das Interesse an der Feststellung des Konkurs-

gläubigerrechts in objektiver Hinsicht . . . . $50-52$

IV. Der Klagegrund insbesondere.

$36-39$

$39-44$

$44-50$

\$ 14: Der Klagegrund in objektiver Hinsicht $\ldots \ldots \ldots \ldots \ldots 53-55$

$\S 15$ : Der Klagegrund in subjektiver Hinsicht ........ $56-59$ 


\section{Kapitel V.}

Die Verfolgung des Widerspruchs.

$\S$ 16: Die vorliegenden Titel $\ldots \ldots \ldots \ldots \ldots \ldots \ldots \ldots \ldots \ldots, 60 \ldots \ldots$

§ 17: Die Wirkungsweite des Titels $\ldots \ldots \ldots \ldots \ldots \ldots \ldots 6$ 65-68

§ 18: Die Mittel der Widerspruchsverfolgung $\ldots \ldots \ldots \ldots \ldots$ 68-74

§ 19: Das präparatorische Verfahren $\ldots \ldots \ldots \ldots \ldots \ldots \ldots .74-76$

$\S 20:$ Das Feststellungsinteresse des titulierten Anmelders 76-79

Kapitel VI.

Die Widerspruchsmehrheit.

§ 21: Einleitung. - Die Zwangsstreitgenossenschaft insbesondere $\ldots \ldots \ldots \ldots \ldots \ldots \ldots \ldots \ldots \ldots \ldots \ldots$ 80 8 82

§ 22: Getrennte Prozesse $\ldots \ldots \ldots \ldots \ldots \ldots \ldots \ldots \ldots \ldots . \quad 82-86$

§ 23: Die Streitgenossenschaft $\ldots \ldots \ldots \ldots \ldots \ldots \ldots \ldots .86 \ldots \ldots$

$\S$ 24: Die Intervention $\ldots \ldots \ldots \ldots \ldots \ldots \ldots \ldots \ldots \ldots .89-93$

Kapitel VII.

§ 25: Der Einfluß der Konkursbeendigung auf die Feststellungsprozesse $\ldots \ldots \ldots \ldots \ldots \ldots \ldots \ldots \ldots \ldots \ldots .93-102$

Kapitel VIII.

§ 26: Die Zuständigkeit der Verwaltung .......... 102-107 